\title{
ON THE DESCRIPTION OF STRUCTURAL DISTRIBUTION AND DIFFUSION OF RADIOACTIVE ELEMENTS IN THE SYSTEM "GLASSY NUCLEAR MAGMA-WATER"
}

\author{
I.R.YUKHNOVSKII, \\ M.V.TokArchuk, I.P.OMELyan, E.M.SOVyAK, R.I.Zhelem \\ Institute for Condensed Matter Physics \\ of the Ukrainian National Academy of Sciences \\ 1 Svientsitskii St., UA-290011 Lviv, Ukraine
}

Received January 31, 1997

\begin{abstract}
State of radioactive and nuclear safety of the object "Shelter" is analysed. Dynamics of active particles in glassy nuclear magma is suggested to be investigated with the aid diffusion equations taking into account radioactive transformations. The simplest model for the system "glassy nuclear magma-water" is formulated and therefore density profiles of active particles are evaluated.
\end{abstract}

\section{Introduction}

During the last 5 years a large number of investigations was made on the Chornobyl's problem, some of the results were published [1-9], but the vast majority are in the archive files [10-25]. All of them point to the cardinal changes of the melted fuel masses - nuclear magma. Nuclear magma - glassy composite, which is formed from the melt of $\mathrm{CaO}, \mathrm{MgO}, \mathrm{Al}_{2} \mathrm{O}_{3}, \mathrm{Fe}_{2} \mathrm{O}_{3}, \mathrm{ZrO}_{2}, \mathrm{SiO}_{2}, \mathrm{H}_{2} \mathrm{O}$ and up to $18 \%$ of $\mathrm{UO}_{2}$ is destroyed, transforming into nuclear dust. One of the important factors of destroying is decreasing temperature of nuclear fuel containing masses, that caused active interaction of water with the nuclear magma $[18,15]$.

Could such changes be predicted? There are many reasons to say - yes. The majority of experiments and investigations concerned processes on the surface of nuclear magma [23]. Obviously, investigations of processes inside magma were not possible due to the technical reasons. But if properly formulated, a complex of theoretical investigations of physico-chemical processes inside magma with the purpose of prognosis of the change of its status versus time in great degree could be able to predict those interior processes, consequences of which we observe now.

These investigations are very important now, because nuclear magma inside the object "Shelter" is substantially non-equilibrium system. A clear description and prognosis of processes within the object "Shelter" based on these invesigations will make possible to take appropriate technical decisions and stabilize the state of the object.

Below we will outline the aspects of the safety problem of the object state. This will be done in the sense which investigations should be carried out in order to construct the model of the processes within the object "Shelter" and, thus to be able to efficiently deal with the problem of safety of the "Object".

Summarizing the results of previous investigations, we can say that inside the object "Shelter" are running non-reversible processes with the increasing tendency of nuclear fuel yield to the water basins inside the object. This is one of the factors of nuclear danger inside the premises of the object. The problem of water interaction with fragments of the destroyed active core of reactor, nuclear magma and nuclear dust is extremely important because: 
- Water interaction with nuclear magma causes substantial increase of neutron effective breeding coefficient $K_{\text {eff }}$, and as a result - local self-keeping nuclear chain reactions are possible.

- Due to the complicated processes of radiolysis the eventual yield of the radioactive materials is observed, what in turn causes uncontrolled transfer of radioactive materials inside the object and beyond its margins.

- When nuclear magma is destroyed radioactive dust is produced (containing uranium, plutonium, americium) - a one more factor of ecological danger of the object.

Processes of destruction of glassy nuclear magma are very complicated. In the first hand it is necessary to say that glassy nuclear magma, which consists on 30$60 \%$ from $\mathrm{SiO}_{2}$ is non-equilibrium amorphous media with large relaxation times, and thus, the external factors, in particularly water can rapidly alter the state of the media. Even in 1986, when the nuclear magma was formed, it was possible to state that it was steadily destroyed versus time. This was due to the active processes of induced radioactive decay of ${ }^{235} \mathrm{U},{ }^{239} \mathrm{Pu},{ }^{241} \mathrm{Pu}$, products of which are hydrogen, tritium, inert gases - neon, crypton, xenon and the whole range of fragments - unstable elements; these by neutron irradiation transform to the stable isotopes and radioactive elements with the large half-lives (more then $10^{5}$ years). Process of radioactive decay of nuclei of ${ }^{235} \mathrm{U},{ }^{239} \mathrm{Pu},{ }^{241} \mathrm{Pu}$ or $\alpha$-, $\beta$-nuclear transformations are accompanied by a substantial yields of energy. This causes intensive processes of energy transfer in the media, and thus non-homogeneous change of temperature. Besides, products of radioactive decays are practically non-homogeneous incorporations in the structure of glassy nuclear magma and according to the theory of dislocations in solid bodies, can cause the substantial structural transformations, recrystallization [26]. Even more complicated processes are connected with the gaseous products of decay - hydrogen, tritium, helium, neon, crypton, xenon. Due to the small solvability of inert gases, inside the material of fuel elements, for example $\mathrm{UO}_{2}$, the excess gas is produced and forms gaseous cavities. The formation and growth of these cavities lead to the swelling of the material. The amount of gas, accumulated in the irradiated media - glassy nuclear magma - could be substantial, what causes deformation and destroys the media. Swelling processes depend from the different simultaneously running processes temperature changes, conditions and intensity of irradiation and properties of the material. The growth of the gaseous pores is a very important factor of the swelling processes. Experimental investigations [4] point to the substantial porouosity of glassy nuclear magma. Process of formation of pores is possible due to gas atoms diffusion in the various defects, cracks, dislocations, diffusion of hydrogen to metals, etc. As a result of the macroscopic diffusion due to the temperature fluctuations gaseous pores may be joined, what leads to even the larger-scaled deformations of material.

The investigations made in 1989-1991 [15,17,19] showed that glassy masses of nuclear magma in the object are loosing their firmness. Obviously, this is a result of non-reversible physico-chemical processes in nuclear magma.

The decrease of temperature on the surface of glassy masses in the average to $40-60{ }^{\circ} \mathrm{C}$, the existance of a large amount of pores and cracks in nuclear magma caused its active interaction with water, which gets inside through the numerous holes in the cover and walls of the object, due to the condensation from air on the inner walls of the object and irrigation of nuclear dust. Water penetrates to cracks and holes in nuclear magma, where process of its radiolysis takes place. This process and its consequences are described in details in Appendices A, B.

Briefly, this causes rapid yield of radioactive material from glassy nuclear magma masses to the water basins of the object, and eventually, the substantial change of concentration versus time of radioactive material inside water basins of the object.

Water penetrates into cracks, pores in nuclear magma wherein it undergoes radiolysis because of $\alpha$-, $\beta$-decays and $\gamma$-radiation. Radiolysis products, water molecules at the interface "nuclear magma- water" take part in complicated hydration $[27,28]$ of uranium $\mathrm{UO}_{2}$, plutonium $\mathrm{PuO}_{2}$ and other oxides of active elements. 
Intensive leaching of uranium from nuclear magma and outlet into reservoirs inside the object "Shelter" occurs. Experimental studies [15,18,22] point to significant time variation of uranium concentration in "Shelter" reservoirs.

We can see that the ratio of cesium, strontium, plutonium and uranium in water eventually grows. Table $1[15]$ presents the minimal and maximal relative amount of radionuclides for the few years period. Table $2[15,18]$ demonstrates the mass ratio of uranium in the water probes within the object according to the different methods of measurements: laserluminiscent, spectrofotometric, X-ray fluorescent. Isotopic composition of uranium was investigated using alpha-spectroscopic and mass-spectroscopic measurements. Generally speaking, all measurements point to the tendecious increase of uranium concentration in the water cavities of the object.

Table 1.

\begin{tabular}{|c|c|c|c|}
\hline $\begin{array}{c}\text { Radio- } \\
\text { nuclides }\end{array}$ & $\begin{array}{c}\text { Period of } \\
\text { observation }\end{array}$ & $\begin{array}{c}\text { Minimal } \\
\text { value }\end{array}$ & $\begin{array}{c}\text { Maximal } \\
\text { value }\end{array}$ \\
\hline${ }^{137}$ Cs & 1991 & $9 \cdot 10^{4}$ & $7 \cdot 10^{7}$ \\
Bk/l & 1992 & $2 \cdot 10^{4}$ & $6 \cdot 10^{7}$ \\
& 1993 & $3 \cdot 10^{3}$ & $9 \cdot 10^{9}$ \\
& 1994 & $2 \cdot 10^{3}$ & $2 \cdot 10^{8}$ \\
& 1995 & - & $6.3 \cdot 10^{7}$ \\
${ }^{90}$ Sr & 1991 & $8 \cdot 10^{3}$ & $2 \cdot 10^{6}$ \\
Bk/l & 1992 & $1 \cdot 10^{3}$ & $1 \cdot 10^{6}$ \\
& 1993 & $1 \cdot 10^{2}$ & $2 \cdot 10^{6}$ \\
& 1994 & $6 \cdot 10^{2}$ & $6 \cdot 10^{6}$ \\
& 1995 & & $5.8 \cdot 10^{6}$ \\
Totally for & 1991 & & 860 \\
plutonium & 1992 & & 3400 \\
Bk/l & 1993 & & 2600 \\
& 1994 & & 2600 \\
& 1995 & & 1811 \\
U & 1991 & & 4900 \\
mkg/l & 1992 & & 23000 \\
& 1993 & 4.0 & 14000 \\
& 1994 & 5.0 & 18000 \\
& 1995 & & 19000 \\
\hline
\end{tabular}

Table 2. Mass ratio of uranium in water, $\mathrm{mg} / \mathrm{l}$.

\begin{tabular}{|c|c|c|c|c|}
\hline $\begin{array}{c}\text { No } \\
\text { of point } \\
\text { for probe }\end{array}$ & $\begin{array}{c}\text { Laserlu- } \\
\text { miniscent } \\
\text { method }\end{array}$ & $\begin{array}{c}\text { Spectro- } \\
\text { fotometric } \\
\text { method }\end{array}$ & $\begin{array}{c}\text { X-ray flu- } \\
\text { orescent } \\
\text { method }\end{array}$ & $\begin{array}{c}\text { Average } \\
\text { values at } \\
\text { point for } \\
3 \text { months }\end{array}$ \\
\hline 1 & $7.0+0.6$ & $6.9+0.6$ & $2.8+0.8$ & 6.0 \\
2 & $3.5+0.4$ & $3.0+0.3$ & 3.7 \\
6 & $9.3+0.5$ & $7.0+0.7$ & $9.4+3.0$ & 10 \\
7 & $1.6+0.3$ & $0.8+0.1$ & $2.6+0.8$ & 1.2 \\
20 & $1.3+0.3$ & 0.8 \\
\hline
\end{tabular}

The so-called yellow spots were investigated by the means of electronic spec- 
troscopy, X-ray phase and X-ray spectral analysis. As a result, it was cleared up that yellow spots are the needle-like crystals of the uranium minerals with the main phases such as: epiyantynite $\mathrm{UO}_{3} 2 \mathrm{H}_{2} \mathrm{O}$, studtite $\mathrm{UO}_{3} 16 \mathrm{CO}_{3} 1.91 \mathrm{H}_{2} \mathrm{O}$, two modifications of $\mathrm{UO}_{4} 4 \mathrm{H}_{2} \mathrm{O}$, retzerfordine $\mathrm{UO}_{2} \mathrm{CO}_{3}$, and unnamed phases $\mathrm{NaUO}_{2}\left(\mathrm{CO}_{3}\right)_{3}$, and also $\mathrm{NaU}\left(\mathrm{CO}_{3}\right)_{2} 2 \mathrm{H}_{2} \mathrm{O}[2,3]$.

All of these minerals have one very significant feature - they are good solutants (in water). So, we have to say that we meet with the non-reversible process of increasing migration of nuclear fuel from nuclear magma to the water cavities inside the object. This is one of the most important factors of nuclear danger of the object.

Aqueous solutions of the radioactive elements salts inside the object are interacting with the different construction materials: concrete and glassy masses of nuclear fuel. It is clear, that the character of such interaction depends very much on the state of the aquateaus solutions. The presence of uranium, plutonium, americium, curium in aquateaus solutions and also their interaction with the fuel-containing masses leads to the intensive processes of water radiolysis as a result of $\alpha$ - and $\beta$ decays and $\gamma$-radiation. In the process of radiolysis chemically active radicals are formed: hydrated electrons and ions $\mathrm{H}^{+}$, groups $\mathrm{OH}^{-}$, molecular compounds $\mathrm{H}_{2}$, $\mathrm{HO}_{2}, \mathrm{H}_{2} \mathrm{O}_{2}$, what largely defines the character of interaction of aquateaus solutions with the different materials inside the object.

We can namely point the following four base types of interaction of water with the nuclear fuel. The first - interaction of water with the fragments of the reactor's active zone. The second - water penetration through holes, cracks and pores inside the nuclear magma. Nuclear magma is very non-homogeneous porous glassy media. Water, getting to the pores, actively interact with the nuclear magma destroying it. The third - the masses of nuclear magma, partly covered by water, which level changes seasonly. The fourth - interaction of water with the nuclear dust.

The particular attention should be paid to the interaction of the aquateaus solutions with the glassy masses of the nuclear fuel. And here we have to give the answer what is the role of the products of radiolysis of water in the process of destroying of these masses, what is the character of their interaction and investigate their influence on the processes of diffusion of uranium, plutonium from nuclear magma into the water solutions. The other important question is how the products of radiolysis influence on the chemical reactions where possible reactants are the ions of uranyl $\mathrm{UO}_{2}^{2+}$, plutonyl $\mathrm{PuO}_{2}^{2+}$, and other complexes containing radioactive elements.

\section{Structural distribution functions and diffusion of parti- cles in the system "nuclear magma-water"}

We are going to treat interaction of nuclear magma with water by the mean of model two-phase system "nuclear magma-water".

Nuclear magma was formed as the result of high temperature melting and gradual solidification of nuclear fuel along with boron, dolomite, lead, sand, clay combinations which were thrown to the reactor to lower the temperature and terminate active nuclear processes. The global problem of nuclear fuel deconcentration was solving. It resulted in glassy inhomogeneous solid medium in the form of avalanches containing a number of highly active nuclides: $\mathrm{U}, \mathrm{Pu}, \mathrm{Cs}, \mathrm{Ce}, \mathrm{Am}, \mathrm{Cm}, \mathrm{Zr}, \mathrm{Sb}$ and their isotopes. Reasoning from the chemical content of probes [1-5] nuclear magma is argued to be a multicomponent glass $[29,30]$ in structure with inherent ionic bond -Si-O-Si-,-O-Si-O-, -Ca-O-, -Al-O-Al-, and belong to sital-like glass: CaO$\mathrm{MgO}-\mathrm{FeO}-\mathrm{Fe}_{2} \mathrm{O}_{3}-\mathrm{Al}_{2} \mathrm{O}_{3}-\mathrm{SiO}_{2}$.

Studies of the percentage composition variations for components of the glass [29] show if there is more than $40 \% \mathrm{SiO}_{2}$ glass structure reveals crystalline character. It should be noted that stability of such a glass depends on the presence of $\mathrm{OH}^{-}$complexes; perhaps glassy nuclear magma contains those complexes. The increase of $\mathrm{OH}^{-}$content brings glassy medium stability down [29]. Taking into account the chemical content of filling materials: dolomite, boron carbonate, natrium phosphate, polymerizing liquids-one could assume the formation of aluminium phosphate glass to be a contender for active wastes matrix materials [31] in chemical content: $\mathrm{NaNO}_{3}, \mathrm{CsNO}_{3}, \mathrm{SrO}, \mathrm{Al}_{2} \mathrm{O}_{3}, \mathrm{Fe}_{2} \mathrm{O}_{3}, \mathrm{AlPO}_{4}, \mathrm{H}_{3} \mathrm{PO}_{4}, \mathrm{Na}_{2} \mathrm{SO}_{4}, \mathrm{NaCl}$, 
$\mathrm{NiO}, \mathrm{Cr}_{2} \mathrm{O}_{3}, \mathrm{UO}_{2}, \mathrm{ZrO}_{2},\left(\mathrm{NH}_{4}\right)_{2} \mathrm{MoO}_{4}$. As was shown in experimental papers [4] till $60 \% \mathrm{SiO}_{2}$ enters into the magma composition. Sophisticated chemical treatment as to iron, nickel, zirconium, niobium, uranium probes extracted from "elephant leg" nuclear magma was carried out in papers $[1,4]$. In particular, X-ray analysis of "elephant leg" samples indicated the presence of $\mathrm{UO}_{2}$-phase, small amounts of the minerals minessotait $\left(\mathrm{Fe}_{2.4} \mathrm{Mg}_{0.4}\right)\left(\mathrm{Si}_{3.95} \mathrm{Al}_{0.95}\right)(\mathrm{OH})_{2.72}$ and diopside $\left(\mathrm{SiO}_{3}\right)_{2}$ as well as possibility of ( $\mathrm{UZr}) \mathrm{O}_{2}$ combinations since molar ratio of uranium to zirconium is close to unity (0.99-1.2) and also new combination-chornobylite (UZr) $\mathrm{SiO}_{4}$. Paper [4] presents the scheme of Cnornobyl glassy avalanches formation after which maximal temperature had ranged up to $2800^{\circ} \mathrm{C}$. When analysing a glassy medium it is important to ascertain the nature of bonds between its basic components; these are oxides with ionic bond in nuclear magma case.

We emphasize here that melts of glassy systems differ from metalic and salt ones in that transition from solid to fluid isn't accompanied by covalent bonds breaking between atoms e.g. Si-O, Al-O, B-O, P-O, i.e. in complexes creating glass "lattice". As this take place dominant influence of covalent bonds causes glass polymeric structure being designed with polyvalent radicals $\left(\mathrm{SiO}_{3}\right)_{n}^{2 n-}$ for silicates, $\left(\mathrm{BO}_{2}\right)_{n}^{(n-1)}-$ for boronides, $\left(\mathrm{PO}_{3}\right)_{n}^{n-}$ for phosphates. Besides that a glassy structure is known to arise in the only case if the viscisity of a melt increases from several poises to $10^{14}$ and higher. Such a great glass viscosity may be attained only for the melts containing a certain quantity of oxides-glassformers. These are oxides with covalent interatomic bonds.

So nuclear magma is a silicate matrix filled by impurities different in chemical content [4] including till $18 \% \mathrm{UO}_{2}$ uranium oxide. Mainly ionic bonds are available between impurities and the silicate matrix thus those impurities might be regarded as ionic clusters (e.g. uranyl ion $\mathrm{UO}_{2}^{2+}$ ) inside the silicate matrix. In connection with it nuclear magma can be represented as the system of interacting ionic clusters with polyvalent radicals $\left(\mathrm{SiO}_{3}\right)_{n}^{2 n-}$ creating polymeric glass structure.

Summarizing everything we can consider the system "nuclear magma-water" as a statistical model of interaction between ionic clusters and water solution. It is clear that advancing a model one should require it to describe physical and chemical processes occuring in the object "Shelter" in the most realistic manner.

What basic processes are needed to be treated when investigating nuclear, physical and chemical transformations in the system "nuclear magma-water"? The category of necessary questions includes the following:

1. Diffusion of ionic clusters incorporating active elements or isolated ions in the silicate matrix with taking account of coulombic, dipole and resonant kinds of interaction;

2. Diffusion of active elements ions from nuclear magma surface to water. Investigation of the interaction between water and nuclear magma taking into consideration both radiolysis because of $\alpha$-, $\beta$-decays, $\gamma$-radiation and chemical reactions.

The diffusion of active elements (in ionic form) from nuclear magma surface to water is affected by both the transport of ions or ionic clusters in the very matrixs and water radiolysis with chemical reactions occuring in it. It is apparent that basic processes leading to the diffusion from the silicate matrix to water take place first of all in the near-surface layer of the system "nuclear magma-water". Water radiolysis has an specifical effect on them in particular products of radiolysis: both radicals, especially hydrogen ions $\mathrm{H}^{+}$or $\mathrm{OH}^{-}$and molecular products: $\mathrm{H}_{2} \mathrm{O}$ $\rightarrow \mathrm{e}_{\mathrm{aq}}^{-}, \mathrm{H}_{\mathrm{aq}}^{+}, \mathrm{OH}_{\mathrm{aq}}^{-}, \mathrm{HO}_{2}, \mathrm{H}_{2}, \mathrm{H}_{2} \mathrm{O}_{2}$; index "aq" stands for hydrated ions. To a great extent the above radiolysis products destroy the silicate matrix increasing the probability of active elements outflow from that into water in ionic form.

When describing the disruption of the silicate matrix an important question is to elucidate destructive mechanisms first of all for magma surface undergoing interaction with water. Interplay of a water solution with a glassy surface is accompanied by a set of interconnected physical and chemical processes: ion-exchange interdiffusion, diffusion of ions $\mathrm{H}^{+}$or $\mathrm{H}_{3} \mathrm{O}^{+}$, hydrolysis of the network siliconoxygen and its corrosion, formation of pores and crackes. According to the paper [44] they may be sketchy described with the aid of chemical rections. 
Ion-exchange diffusion can be schematized by the reaction

$$
\mathrm{L}^{+}+\equiv \mathrm{SiO}^{-} \mathrm{M}^{+} \rightleftarrows \equiv \mathrm{SiO}^{-} \mathrm{L}^{+}+\mathrm{M}^{+}
$$

wherein $\mathrm{L}^{+}$is e.g. $\mathrm{H}_{3} \mathrm{O}^{+}$or $\mathrm{H}^{+}, \mathrm{M}^{+}$-ions of metals. As a result of the reaction (1) having equilibrium point to be shifted in fact entirely towards the right promoting hydrated complexes $\equiv \mathrm{SiOH} \cdots \mathrm{OH}$, leaching and formation of the first hydrated layer occurs, which interact afterwards with glassy surface according to the reaction:

$$
\equiv \mathrm{SiO}^{-} \mathrm{M}^{+}+\equiv \mathrm{SiOH} \rightleftarrows \equiv \mathrm{SiOH}+\equiv \mathrm{SiO}^{-} \mathrm{M}^{+}
$$

In this manner the ion-exchange layer is formed with inherent interdiffusion of ions $\mathrm{H}^{+}$and $\mathrm{M}^{+}$. Interaction of water molecules with a silicate surface can be described by chemical reactions

$$
\equiv \mathrm{SiO}^{-} \mathrm{M}^{+}+\mathrm{H}_{2} \mathrm{O} \rightleftarrows \equiv \mathrm{SiOH}+\mathrm{OH}^{-}+\mathrm{M}^{+}
$$

which result in outlet of metal ions into the solution while hydroxide complexes $\mathrm{OH}^{-}$take part in further reactions of the depolymerization of silicon-oxygen network.

$$
\begin{aligned}
& \equiv \mathrm{Si}-\mathrm{O}-\mathrm{Si} \equiv+\mathrm{OH}^{-} \rightleftarrows \equiv \mathrm{SiO}^{-}+\equiv \mathrm{SiOH} \\
\equiv \mathrm{SiO}^{-}+ & \equiv \mathrm{SiOH}+\mathrm{H}_{2} \mathrm{O} \rightleftarrows 2 \equiv \mathrm{SiOH}+\mathrm{OH}^{-} \quad \text { and so on }
\end{aligned}
$$

Reactions of this kind can proceed from glassy magma surface to an alkali active solution ( $\mathrm{pH}=9 \div 11$ for reservoirs of the object "Shelter"). Apart from reactions 3 water molecules are able to destroy the silicon-oxygen network due to interaction between oxygen ions of water and $\mathrm{Si}$ atoms and at the same time $\mathrm{H}^{+}$ions with oxygen atoms of silicon-oxygen network $\equiv \mathrm{Si}-\mathrm{O}-\mathrm{H}$

$$
\equiv \mathrm{Si}-\mathrm{O}-\mathrm{Si} \equiv+\mathrm{H}-\mathrm{OH} \rightarrow \equiv \mathrm{Si}-\mathrm{O} \cdots \mathrm{Si} \equiv+\mathrm{H} \cdots \mathrm{OH} \rightarrow \equiv \mathrm{Si}-\mathrm{O}-\mathrm{H}+\equiv \mathrm{Si}-\mathrm{OH},
$$

A set of reactions (3-6) represents the hydrolysis and depolymerization of the silicon-oxygen network. It brings about the formation of hydrated complexes $=\mathrm{Si}(\mathrm{OH})_{2},-\mathrm{Si}(\mathrm{OH})_{3}, \mathrm{Si}(\mathrm{OH})_{4}, \mathrm{Si}(\mathrm{OH})_{6}^{2-}$ which pass to the solution. In such a manner the corrosion of silicon-oxygen network occurs being enhanced by hydrogen ions $\mathrm{H}^{+}$, hydrated complexes $\mathrm{OH}^{-}$, which arise additionally as a result of radiolysis, hydrolysis and hydration of uranium $\mathrm{UO}_{2}$, plutonium $\mathrm{PuO}_{2}$ and other oxides [39-43].

For the description of interplay of a water solution with glassy nuclear magma according to reactions (1)-(6) we need to formulate a physical model to base on it researches into structural functions, their diffusion from one phase to another and reaction constants. The prelude of any microscopic treatment is the structural information in the form of density profiles and higher distribution functions. The most accepted way lies in the use of Ornstein-Zernike equation modified for inhomogeneous fluids. But it needs a certain closure. Most of known closures don't enable to obtain an analytical solution. Moreover the more efficient closure relation is the more tedious numerical computations should be carried out. So we prefer BGY method and the matter is in the following.

Active elements will be supposed to be present in water in small amounts. Within this model active elements particles $\left(\mathrm{UO}_{2}^{2+}, \mathrm{Cs}^{+}, \mathrm{Sr}^{2+}\right)$ are considered as charged hard spheres having the overall charge to be compensated according to the electroneutrality condition by negative $\mathrm{OH}^{-}$-groups in continuous medium with the dielectric constant $\varepsilon=81$ (water).

Active water solutions inside the object "Shelter" contact mostly with nuclear magma, concrete, clay and numerous constructive materials. To predict the destroyment and investigate the diffusion of active particles it is necessary to know the structure of a solution near these materials. The problem reduces to the treatment of the solution model near a hard wall outlined above, which is along with solvent a continuous medium with the dielectric constant $\varepsilon=1 \div 15$ (glass-like medium, clay, concrete). In this approach profiles are affected by both structural ordering caused by own sizes and the presence of surface and electrostatic images 
to be most pronounced at small distances. However their consecutive consideration is fairly intricate problem. To this end we used the first equation of BGYchain modified to describe image charges. These latter are assumed to be fictitious charged particles inside the wall (glass-like medium, clay, concrete, volume $V^{\prime}$ ), which have charges $\frac{\varepsilon_{p}-\varepsilon_{\mathrm{c}}}{\varepsilon_{p}+\varepsilon_{\mathrm{c}}} Z_{i} e$ and sizes $\sigma_{i}$, wherein $Z_{i} e, \sigma_{i}$ are charges and sizes of particles in the solution (volume $V$ ). If to apply the method given in [37] we arrive at the following equation:

$$
\begin{aligned}
& \frac{\mathrm{d} f_{a}\left(z_{1}\right)}{\mathrm{d} z_{1}}+\frac{\mathrm{d} U_{1}^{a}\left(z_{1}\right)}{\mathrm{d} z_{1}} f_{a}\left(z_{1}\right) \\
& +\sum_{c} \rho_{c} \int_{V} \mathrm{~d} \boldsymbol{r}_{2 c} \frac{\partial}{\partial z_{1}}\left(U_{\mathrm{hs}}^{a c}\left(r_{12}\right)+U_{\mathrm{C}}^{a c}\left(r_{12}\right)\right) F_{a c}\left(z_{1 a}, z_{2 c}, r_{2 c}\right) \\
& +\sum_{c} \rho_{c}^{\prime} \int_{V^{\prime}} \mathrm{d} \boldsymbol{r}_{2 c}^{\prime} \frac{\partial}{\partial z_{1}} U_{\mathrm{im}}^{a c}\left(r_{12}^{\prime}\right) F_{a c}^{\prime}\left(z_{1 a}, z_{2 c}^{\prime}, r_{2 c}^{\prime}\right)=0,
\end{aligned}
$$

wherein $f_{a}\left(z_{1}\right), U_{1}^{a}\left(z_{1}\right)$ - the profile and interaction potential of the ath species particle with the wall; $F_{a c}, U_{\mathrm{hs}}^{a c}, U_{\mathrm{C}}^{a c}, U_{\mathrm{im}}^{a c}$ - the binary distribution function for particles of species $a, c$, hard sphere potentials, Coulomb interaction between particles and between particles and images respectively; $\rho_{c}, \rho_{c}^{\prime}$ the density of species $c$ particles and their images. It is easily seen that the second integral term takes into account image effects on equal terms. But at small concentrations integral terms are minor (pair correlation isn't essential) so ionic distribution near the surface is determined by the potential $U_{1}^{a}\left(z_{1}\right)$ that is advantageous to use as screened potential. The problem of point particles screened potential near a hard wall has rigorous analytical solution [38,39]. In the case of ion-ion interaction the result is as follows:

$$
g\left(\boldsymbol{r}_{1}, \boldsymbol{r}_{2}\right)=\mp \frac{Z_{1} Z_{2} e^{2}}{\varepsilon_{p}}\left\{\frac{e^{-\kappa r_{12}}}{r_{12}}+\frac{\varepsilon_{p}-\varepsilon_{\mathrm{c}}}{\varepsilon_{p}+\varepsilon_{\mathrm{c}}} \frac{e^{-\kappa r_{12}^{\prime}}}{r_{12}^{\prime}}\right\}
$$

with $r_{12}$-distance between particles, $r_{12}^{\prime}$-that between the first particle and the image of the second one. It is evident that potential consists of the bulk part dependent on $r_{12}$ and the surface one. The problem of bulk screened potential evaluation for arbitrary amount of ions having distinct sizes and valences is solved in [38]. We make use of the result for small concentrations in view of that the potential of an inhomogeneous system is expressed through bulk ones as is seen from (8). Thus

$$
U_{1}^{a}\left(z_{1}\right)=\frac{\varepsilon_{p}-\varepsilon_{\mathrm{c}}}{\varepsilon_{p}+\varepsilon_{\mathrm{c}}} \frac{\left(Z_{1}^{a} e\right)^{2}}{\varepsilon_{p}} \frac{1}{2 z}\left[\frac{2 \Gamma}{\kappa}\right]^{2} \exp \left\{-2 \Gamma\left(2 z-\sigma_{a}\right)\right\}, \quad z>\sigma_{a} / 2,
$$

in which $2 \Gamma$-new screening radius to be specified by the following equation system

$$
\begin{gathered}
4 \Gamma^{2}=\frac{e^{2}}{\varepsilon_{p}} \sum_{a} \rho_{a} X_{a}^{2}, \quad X_{a}=\frac{Z_{a}-\frac{\pi}{2} \frac{\sigma_{a}^{2}}{1-\eta} P_{m}}{1+\Gamma \sigma_{a}}, \\
P_{m}=\frac{\sum_{a} \frac{\rho_{a} \sigma_{a} Z_{a}}{1+\Gamma \sigma_{a}}}{1+\frac{\pi}{2(1-\eta)} \sum_{a} \frac{\rho_{a} \sigma_{a}^{3}}{1+\Gamma \sigma_{a}}}, \quad \eta=\frac{\pi}{6} \sum_{a} \rho_{a} \sigma_{a}^{3}, \quad \rho_{a}=N_{a} / V,
\end{gathered}
$$

wherein $a$ stands for active ions including negative $\mathrm{OH}^{-}$-groups with the density to satisfy the general electroneutrality condition for the system

$$
\sum_{a} \rho_{a} Z_{a}^{2}=0 .
$$


Then the solution of $(7)$ under the condition $f_{a}(\infty)=1$ is the following

$$
f_{a}(z)=\exp \left(-U_{1}^{a}(z)\right) \text {. }
$$

Figures 1, 2, 3 show qualitative profiles for ions $\mathrm{UO}_{2}^{2+}, \mathrm{Cs}^{+}, \mathrm{Sr}^{2+}$ to be estimated at various concentrations with the aid of (10). It can be seen that small concentrations of active elements result in essential wall effect even at long distance while large ones bring about screening due to which the system quickly attains bulk properties. Moreover in the case of small concentrations ionic behaviour is determined by their valences only- curves for bivalent uranilum and strontium coincide but differ from that for univalent cesium. At high concentrations ionic sizes reveal themselves uranilum and strontium assume individual distribution features at the interface "water solution-glassy medium".

To describe the diffusion of complex particles into water from nuclear magma realistically we are going to complicate the system by considering as the model comprising $M$ species with $N_{a}$ particles of each one, which combine $X_{\alpha}$ sites (each site carries the charge $e z_{\alpha}^{a}$ ) interacting between themselves and water molecules. Subsystem "water" with dielectric constant $\varepsilon_{\mathrm{B}}$ is regarded as a total combination of water molecules $\mathrm{H}_{2} \mathrm{O}$ and ionic radicals, in particular, hydrogen ions $\mathrm{H}^{+}$and complex $\mathrm{OH}^{-}$and labelled as particles of $s$ species formed by $X_{\alpha}$ charged sites in the volume $V_{2}$. It is clear that the water solution can harbor other ions or molecular complexes interacting with nuclear magma particles. At a certain stage of studies they might be taken into account. Change in charged sites density which should be incorporated to create an active element (e.g. those in ionic form $\mathrm{UO}_{2}^{2+}, \mathrm{PuO}_{2}^{2+}$ ) in the silicate matrix may be described by generalized diffusion equations for the two-phase system "nuclear magma-water". Similar equations were obtained in our papers [32,33]. In the case of quasinonequilibrium diffusion this equation system is as follows:

a) the phase "nuclear magma", volume $V_{1}$ :

$$
\begin{aligned}
& \frac{\partial}{\partial t} n_{1}^{\alpha a}\left(\boldsymbol{r}_{1} ; t\right)= \\
& -\sum_{\beta, b} \int_{V_{1}} \mathrm{~d} \boldsymbol{r}_{1}^{\prime} \int_{-\infty}^{t} \mathrm{~d} t^{\prime} \mathrm{e}^{\varepsilon\left(t^{\prime}-t\right)} \frac{\partial}{\partial \boldsymbol{r}_{1}} D_{11}^{\alpha a, \beta b}\left(\boldsymbol{r}_{1}, \boldsymbol{r}_{1}^{\prime} ; t, t^{\prime}\right) \frac{\partial}{\partial \boldsymbol{r}_{1}^{\prime}} \delta n_{1}^{\beta b}\left(\boldsymbol{r}_{1}^{\prime} ; t^{\prime}\right) \\
& -\sum_{\beta, b} \int_{V_{2}} \mathrm{~d} \boldsymbol{r}_{2}^{\prime} \int_{-\infty}^{t} \mathrm{~d} t^{\prime} \mathrm{e}^{\varepsilon\left(t^{\prime}-t\right)} \frac{\partial}{\partial \boldsymbol{r}_{1}} D_{12}^{\alpha a, \beta b}\left(\boldsymbol{r}_{1}, \boldsymbol{r}_{2}^{\prime} ; t, t^{\prime}\right) \frac{\partial}{\partial \boldsymbol{r}_{2}^{\prime}} \delta n_{2}^{\beta b}\left(\boldsymbol{r}_{2}^{\prime} ; t^{\prime}\right) \\
& -\sum_{s} \int_{V_{2}} \mathrm{~d} \boldsymbol{r}_{2}^{\prime} \int_{-\infty}^{t} \mathrm{~d} t^{\prime} \mathrm{e}^{\varepsilon\left(t^{\prime}-t\right)} \frac{\partial}{\partial \boldsymbol{r}_{1}} D_{12}^{\alpha a, \beta s}\left(\boldsymbol{r}_{1}, \boldsymbol{r}_{2}^{\prime} ; t, t^{\prime}\right) \frac{\partial}{\partial \boldsymbol{r}_{2}^{\prime}} \delta n_{2}^{\beta s}\left(\boldsymbol{r}_{2}^{\prime} ; t^{\prime}\right),
\end{aligned}
$$

b) the phase "water", volume $V_{2}$ :

$$
\begin{aligned}
& \frac{\partial}{\partial t} n_{2}^{\alpha s}\left(\boldsymbol{r}_{2} ; t\right)= \\
& -\sum_{\beta, b} \int_{V_{1}} \mathrm{~d} \boldsymbol{r}_{1}^{\prime} \int_{-\infty}^{t} \mathrm{~d} t^{\prime} \mathrm{e}^{\varepsilon\left(t^{\prime}-t\right)} \frac{\partial}{\partial \boldsymbol{r}_{2}} D_{21}^{\alpha s, \beta b}\left(\boldsymbol{r}_{2}, \boldsymbol{r}_{1}^{\prime} ; t, t^{\prime}\right) \frac{\partial}{\partial \boldsymbol{r}_{1}^{\prime}} \delta n_{1}^{\beta b}\left(\boldsymbol{r}_{1}^{\prime} ; t^{\prime}\right) \\
& -\sum_{\beta, b} \int_{V_{2}} \mathrm{~d} \boldsymbol{r}_{2}^{\prime} \int_{-\infty}^{t} \mathrm{~d} t^{\prime} \mathrm{e}^{\varepsilon\left(t^{\prime}-t\right)} \frac{\partial}{\partial \boldsymbol{r}_{2}} D_{22}^{\alpha s, \beta b}\left(\boldsymbol{r}_{2}, \boldsymbol{r}_{2}^{\prime} ; t, t^{\prime}\right) \frac{\partial}{\partial \boldsymbol{r}_{2}^{\prime}} \delta n_{2}^{\beta b}\left(\boldsymbol{r}_{2}^{\prime} ; t^{\prime}\right) \\
& -\sum_{s^{\prime}} \int_{V_{2}} \mathrm{~d} \boldsymbol{r}_{2}^{\prime} \int_{-\infty}^{t} \mathrm{~d} t^{\prime} \mathrm{e}^{\varepsilon\left(t^{\prime}-t\right)} \frac{\partial}{\partial \boldsymbol{r}_{2}} D_{22}^{\alpha s, \beta s^{\prime}}\left(\boldsymbol{r}_{2}, \boldsymbol{r}_{2}^{\prime} ; t, t^{\prime}\right) \frac{\partial}{\partial \boldsymbol{r}_{2}^{\prime}} \delta n_{2}^{\beta s^{\prime}}\left(\boldsymbol{r}_{2}^{\prime} ; t^{\prime}\right),
\end{aligned}
$$




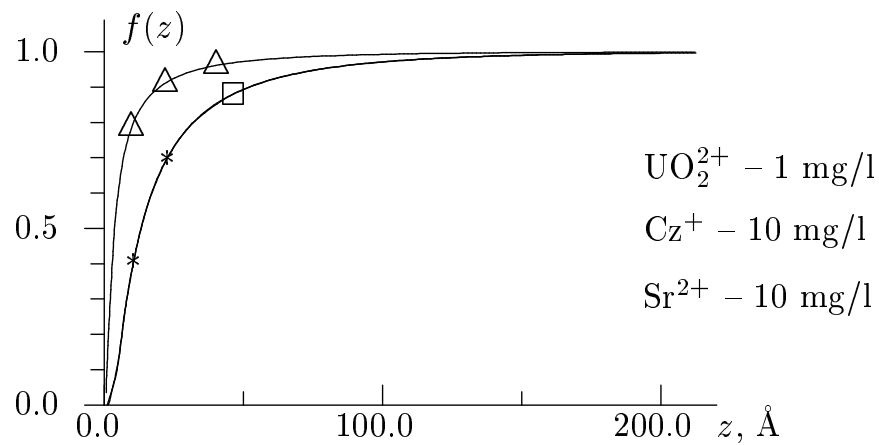

Figure 1. Qualitative distribution functions of active particles near the interface "water solution-glass-like medium". Curves are labelled by: $*$ for $\mathrm{UO}_{2}^{2+}, \triangle$ for $\mathrm{Cz}^{+}, \square$ for $\mathrm{Sr}^{2+}$.

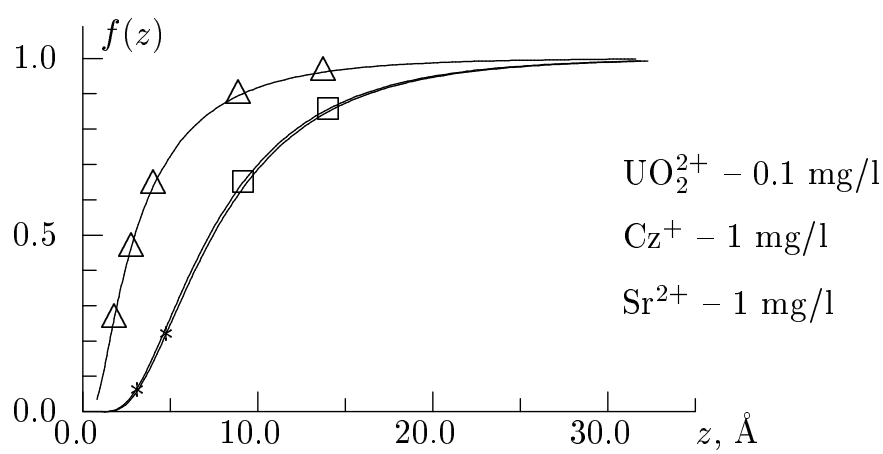

Figure 2. The same as in figure 1 but for distinct concentrations.

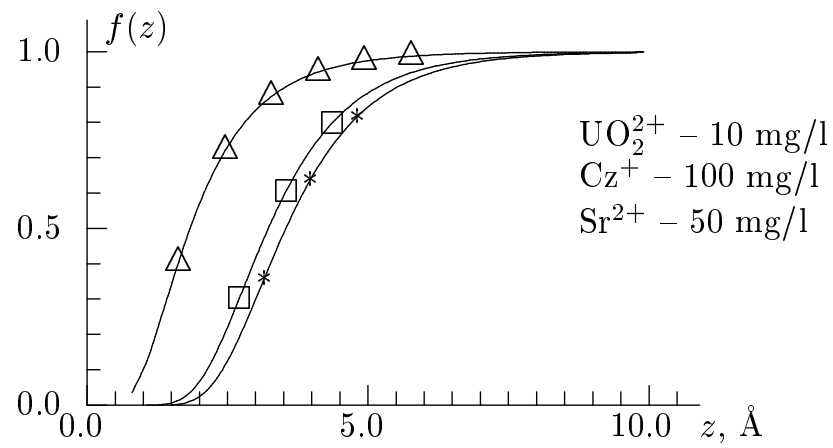

Figure 3 . The same as in figure 1 but for distinct concentrations. 
and

$$
\begin{aligned}
& \frac{\partial}{\partial t} n_{2}^{\alpha a}\left(\boldsymbol{r}_{2} ; t\right)= \\
& -\sum_{\beta, b} \int_{V_{1}} \mathrm{~d} \boldsymbol{r}_{1}^{\prime} \int_{-\infty}^{t} \mathrm{~d} t^{\prime} \mathrm{e}^{\varepsilon\left(t^{\prime}-t\right)} \frac{\partial}{\partial \boldsymbol{r}_{2}} D_{21}^{\alpha a, \beta b}\left(\boldsymbol{r}_{2}, \boldsymbol{r}_{1}^{\prime} ; t, t^{\prime}\right) \frac{\partial}{\partial \boldsymbol{r}_{1}^{\prime}} \delta n_{1}^{\beta b}\left(\boldsymbol{r}_{1}^{\prime} ; t^{\prime}\right) \\
& -\sum_{\beta, b} \int_{V_{2}} \mathrm{~d} \boldsymbol{r}_{2}^{\prime} \int_{-\infty}^{t} \mathrm{~d} t^{\prime} \mathrm{e}^{\varepsilon\left(t^{\prime}-t\right)} \frac{\partial}{\partial \boldsymbol{r}_{2}} D_{22}^{\alpha a, \beta b}\left(\boldsymbol{r}_{2}, \boldsymbol{r}_{2}^{\prime} ; t, t^{\prime}\right) \frac{\partial}{\partial \boldsymbol{r}_{2}^{\prime}} \delta n_{2}^{\beta b}\left(\boldsymbol{r}_{2}^{\prime} ; t^{\prime}\right) \\
& -\sum_{s} \int_{V_{2}} \mathrm{~d} \boldsymbol{r}_{2}^{\prime} \int_{-\infty}^{t} \mathrm{~d} t^{\prime} \mathrm{e}^{\varepsilon\left(t^{\prime}-t\right)} \frac{\partial}{\partial \boldsymbol{r}_{2}} D_{22}^{\alpha a, \beta s}\left(\boldsymbol{r}_{2}, \boldsymbol{r}_{2}^{\prime} ; t, t^{\prime}\right) \frac{\partial}{\partial \boldsymbol{r}_{2}^{\prime}} \delta n_{2}^{\beta s}\left(\boldsymbol{r}_{2}^{\prime} ; t^{\prime}\right),
\end{aligned}
$$

$\varepsilon \rightarrow+0$ after the thermodynamical limit. In Eqs (11)-(13)

$$
\begin{aligned}
\delta n_{\xi}^{\alpha a}\left(\boldsymbol{r}_{\xi} ; t\right) & =\left\langle\delta \hat{n}_{\xi}^{\alpha a}\left(\boldsymbol{r}_{\xi}\right)\right\rangle^{t} \\
\delta \hat{n}_{\xi}^{\alpha a}\left(\boldsymbol{r}_{\xi}\right) & =\hat{n}_{\xi}^{\alpha a}\left(\boldsymbol{r}_{\xi}\right)-\left\langle\hat{n}_{\xi}^{\alpha a}\left(\boldsymbol{r}_{\xi}\right)\right\rangle_{0}, \\
\hat{n}_{\xi}^{\alpha a}\left(\boldsymbol{r}_{\xi}\right) & =\sum_{j=1}^{N_{a}} \delta\left(\boldsymbol{r}_{j}^{\alpha}-\boldsymbol{r}_{\xi}\right) .
\end{aligned}
$$

It should be remembered that sites densities $n_{\xi}^{\alpha a}\left(\boldsymbol{r}_{\xi} ; t\right)$ are not irrespective of each other as they compose complex particles so

$$
\frac{n_{\xi}^{\alpha a}\left(\boldsymbol{r}_{\xi} ; t\right)}{X_{\alpha}}=\frac{n_{\xi}^{\beta a}\left(\boldsymbol{r}_{\xi} ; t\right)}{X_{\beta}}=n_{\xi}^{a}\left(\boldsymbol{r}_{\xi} ; t\right)
$$

in which $n_{\xi}^{a}$ is related to $f_{a}$ from (7) through the density factor

$$
n_{\xi}^{a}=\frac{N_{a}}{V_{\xi}} f_{a}
$$

Eq. (16) defines density for the $\alpha$ th site carried by the ath species particle in the phase $\xi=1,2 ;\langle\ldots\rangle^{t}$ - averaging with a total nonequilibrium distribution function for particles of whole system, $\langle\ldots\rangle_{0}$ - averaging with a total equilibrium distribution function $\rho_{0}$. Microscopic density for active particles may be conveniently defined in the following way

$$
\hat{n}_{\xi}^{\alpha a}\left(\boldsymbol{r}_{\xi}\right)=\sum_{j=1}^{N_{a}} \delta\left(\boldsymbol{r}_{j}^{\alpha}-\boldsymbol{r}_{\xi}\right)\left(1-\lambda_{a}^{*}\right)
$$

in which $\lambda_{a}^{*}=\lambda_{a} t$ - dimensionless spontaneous decay constant or that for $\alpha-\beta$ decay of curium, plutonium, americium. Evidently neutron capturing by active elements (uranium, curium, plutonium, americium) and induced fission can't be taken into account in this way since constants of these processes depend to a great extent on neutron distribution function and their fluxes. The problems are to be considered in detail. Respectively

$$
\hat{n}_{\xi}^{\beta s}\left(\boldsymbol{r}_{\xi}\right)=\sum_{l=1}^{N_{s}} \delta\left(\boldsymbol{r}_{l}^{\beta}-\boldsymbol{r}_{\xi}\right)
$$


- microscopic density of water molecules or dissociated ions $\left(\mathrm{H}^{+}, \mathrm{OH}^{-}\right)$and radicals.

$$
\begin{aligned}
D_{\xi f}^{\alpha a, \beta b}\left(\boldsymbol{r}_{\xi},\right. & \left.\boldsymbol{r}_{f}^{\prime} ; t, t^{\prime}\right)=\sum_{\gamma, c} \sum_{f^{\prime}} \int_{V_{f^{\prime}}} \mathrm{d} \boldsymbol{r}_{f^{\prime}}^{\prime \prime}\left\langle\left(1-P_{M}\right) \hat{\boldsymbol{J}}_{\xi}^{\alpha a}\left(\boldsymbol{r}_{\xi}\right) \times\right. \\
& \left.\times T\left(t, t^{\prime}\right)\left(1-P_{M}\right) \hat{\boldsymbol{J}}_{f^{\prime}}^{\gamma c}\left(\boldsymbol{r}_{f^{\prime}}^{\prime \prime}\right)\right\rangle_{0}\left(\tilde{F}^{-1}\left(\boldsymbol{r}^{\prime \prime}, \boldsymbol{r}^{\prime}\right)\right)_{f^{\prime} f}^{\gamma c, \beta b}
\end{aligned}
$$

generalized diffusion coefficients for charged sites in particular $D_{11}^{\alpha a, \beta b}$ - in nuclear magma, $D_{12}^{\alpha a, \beta b}$-governs the diffusion from nuclear magma into water; $D_{22}^{\alpha a, \beta b}$ - in water with

$$
\hat{\boldsymbol{J}}_{\xi}^{\alpha a}(\boldsymbol{r})=\sum_{j=1}^{N_{a}} \boldsymbol{p}_{j}^{\alpha} \delta\left(\boldsymbol{r}_{j}^{\alpha}-\boldsymbol{r}_{\xi}\right)
$$

to be momentum density for charged sites in the respective phase $\xi$,

$$
P_{M} A=\sum_{\alpha, a \xi} \sum_{\beta, b f} \int_{V_{\xi}} \mathrm{d} \boldsymbol{r}_{\xi} \int_{V_{f}} \mathrm{~d} \boldsymbol{r}_{f}^{\prime}\left\langle A \hat{n}_{\xi}^{\alpha a}\left(\boldsymbol{r}_{\xi}\right)\right\rangle_{0}\left(\tilde{F}^{-1}\left(\boldsymbol{r}, \boldsymbol{r}^{\prime}\right)\right)_{\xi f}^{\alpha a, \beta b} \hat{n}_{f}^{\beta b}\left(\boldsymbol{r}_{f}^{\prime}\right)
$$

- Mori projection operator, $T_{0}(t)=\exp \left\{\left(1-P_{M}\right) \mathrm{i} L_{N} t\right\}-$ time evolution operator, i $L_{N^{-}}$the Liouville operator to be appropriate to the system's Hamiltonian

$$
\begin{gathered}
H=\sum_{a} \sum_{\alpha j}^{N_{a}, X_{a}} \frac{\left(p_{j}^{\alpha}\right)^{2}}{2 m_{a}}+\frac{1}{2} \sum_{a, b} \sum_{\alpha, \beta} \sum_{i, j} \Phi_{a b}\left(\boldsymbol{r}_{i j}^{\alpha \beta}\right)+\sum_{s} \sum_{i=1}^{N_{s}} \frac{p_{i}^{2}}{2 m_{s}} \\
+\frac{1}{2} \sum_{s, s^{\prime}} \sum_{i, l} \Phi_{s s^{\prime}}\left(\boldsymbol{r}_{i l}\right)+\sum_{a} \sum_{\alpha, j}^{N_{a}, X a} \sum_{s} \sum_{l=1}^{N_{s}} \Phi_{a s}\left(\boldsymbol{r}_{j l}^{\alpha}\right)+\sum_{a, \alpha, j}^{N_{a}, X_{a}} \varphi_{a}^{(1)}\left(z_{j}^{\alpha}\right),
\end{gathered}
$$

wherein $\Phi_{a b}\left(\boldsymbol{r}_{i j}^{\alpha \beta}\right)$ - potential of interaction between charged sites, $\Phi_{a s}\left(\boldsymbol{r}_{j l}^{\alpha}\right)$ that for charged sites and water molecules (or ions $\mathrm{H}^{+}, \mathrm{OH}^{-}$, or radicals $\mathrm{HO}_{2}$, $\left.\mathrm{H}_{2} \mathrm{O}_{2}, \mathrm{H}_{2}\right), \varphi_{a}^{(1)}\left(z_{j}^{\alpha}\right)$ - potential at the interface "nuclear magma-water". Functions $\left(\tilde{F}^{-1}\left(\boldsymbol{r}, \boldsymbol{r}^{\prime}\right)\right)_{\xi f}^{\alpha a, \beta b}$ make up the matrix $\tilde{F}^{-1}\left(\boldsymbol{r}, \boldsymbol{r}^{\prime}\right)$, to be the reverse of $\tilde{F}\left(\boldsymbol{r}, \boldsymbol{r}^{\prime}\right)$. This latter consists of pair equilibrium distribution functions for charged sites

$$
F_{\xi f}^{\alpha a, \beta b}\left(\boldsymbol{r}, \boldsymbol{r}^{\prime}\right)=\left\langle\hat{n}_{\xi}^{\alpha a}(\boldsymbol{r}) \hat{n}_{f}^{\beta b}\left(\boldsymbol{r}^{\prime}\right)\right\rangle_{0} .
$$

At the same time in Eqs (11)-(13) $D_{21}^{\alpha s, \beta b}, D_{22}^{\alpha s, \beta b}, D_{12}^{\alpha a, \beta s}$ are interdiffusion coefficients for nuclear magma charged sites, water molecules, ions $\mathrm{H}^{+}, \mathrm{OH}^{-}$and radicals $\mathrm{H}_{2}, \mathrm{H}_{2} \mathrm{O}_{2}, \mathrm{HO}_{2}$. In the subsystem "water" it is necessary to investigate interdiffusion coefficients for charged sites of $\mathrm{UO}_{2}^{2+}, \mathrm{Pu}_{2}^{2+}$ and other ions and water molecules, ions $\mathrm{H}^{+}, \mathrm{OH}^{-}$and radicals $-D_{22}^{\alpha a, \beta b}, D_{22}^{\alpha a, \beta s}$ entering corresponding constants of chemical reactions. It is important in view of hydration research for ions $\mathrm{UO}_{2}^{2+}, \mathrm{PuO}_{2}^{2+}$ at their outlet from nuclear magma into water because uranyl and plutonyl reveal a polymeric structure if uranium or plutonium concentration in water increases (it does take place [15]). The dynamical behaviour of those combinations is undetermined if to enhance uranium or plutonium concentration. But Eqs (11)-(13) can yield the information by calculating generalized diffusion coefficients (19) for the system "nuclear magma-water" and taking account of peculiarities of interaction between the medium and water solution. A remarkable point at studies of diffusion coefficients $D_{\xi f}^{\alpha a, \beta b}, D_{\xi f}^{\alpha a, \beta s}$ in the subsystem "water" is consideration of radiolysis in it induced by $\alpha$-, $\beta$-decays and $\gamma$-radiation. 


\section{References}

[1] Borovoi A.A., Galkin B.Ya. et al. New formed products as the result of interaction between fuel and constructive materials at the 4th block of Chornobyl atomic power station. // Radiokhimiya, 1990, No 6, p. 103-113; 1991, No 4, p. 177-196 (in Russian).

[2] Anderson E.B., Burakov B.E., Pazukhin E.M. Secondary mutation of fuel containing masses of Chornobyl atomic power plant 4-th reactor. // Radiokhimiya, 1992, No 5, p. 135-138 (in Russian).

[3] Anderson E.B., Borovoi A.A., Burakov B.E., Krinitsyn A.P., Pazukhin E.M., Checherov K.P. Technogeneous products of interaction of fuel and constructing materials, obtained after Chornobyl disaster. // Radiokhimiya, 1992, No 5, c. 144-155 (in Russian).

[4] Pazukhin E.M. Lava-shaped fuel containing mediums at the 4-th block of Chornobyl atomic power station: Topography, physical and chemical properties, version as to formation. // Radiokhimiya, 1994, vol. 34, No 2, p. 97-142 (in Russian).

[5] Abalin S.S., Bar'yakhtar V.G., Belyajev S.T., Borovoi A.A. et al. Ensuring ecological safety at the object "Shelter" (Studies during 1990-1991). // Reports of Ukrainian Academy of Sciences, 1994, No 1, p. 116-121 (in Ukrainian).

[6] Borovoi A.A. Chornobyl "Shelter". // Priroda, 1994, No 4, p. 62-70 (in Russian).

[7] Kiselyov A.N., Nenaglyadov A.Yu., Surin A.I. et al. Experimental researches in lavashaped fuel containing mediums at the 4 th block of Chornobyl atomic power station. Moscow, 1992, 120 p. (Preprint of Atomic Energy Institute - 5533/3) (in Russian).

[8] Kiselyov A.N., Surin A.I., Checherov K.P. Results of supplementary investigations on accumulations of lava-shaped fuel containing mediums at the 4-th block of Chornobyl atomic power station. Moscow, 1994, 59 p. Preprint of Atomic Energy Institute $5783 / 3$ (in Russian).

[9] Yukhnovskii I.R., Tokarchuk M.V. The problems of the 4-th powerblock of Chornobyl NPS I. Review. Lviv, 1995. Preprint ICMP-95-3U, 40 p. (in Ukrainian).

[10] Working through methods for radiochemical extraction of uranium from fuel containing samples and carrying out mass- spectroelectric measurements of uranium's isotopic content with the purpose of the straightforward burn-up determination for the nuclear fuel inside a fuel containing medium. Report. Inventory No 11.07/118 since 12.03.1991. Kurchatov Institute of Atomic Power , 1991, $21 \mathrm{p}$ (in Russian).

[11] Report on scientific and technical work "Nuclear safety of the object "Shelter" on the basis of investigations of breakdown processes dynamics". Inventory No 1515, Minsk, 1991 (in Russian).

[12] Calculation and experimental investigations of neutron fields characteristics in the places of accumulation of lava-shaped fuel containing masses inside premises 304/2 and 305/2 of the object "Shelter". Report. Minsk, 1994, 77 p. (in Russian).

13] Year report of the department for working through methods and analysis systems for radioactive technologies. International scientifical and technical center of National Ukrainian Academy of Sciences "Shelter", 1994, 44 p. (in Russian).

[14] Results of papers fulfilled by the department of radioactive monitoring "Shelter" in 1994. Report of the department for nuclear and radioactive safety. Chornobyl, 1994, 149 p. (in Russian).

[15] Main scientifical and technical results obtained at the department for nuclear and radioactive safety in 1994. Chornobyl, 1994, 137 p. (in Russian).

[16] On the activity of emergency processes department at International scientifical and technical center of National Ukrainian Academy of Sciences "Shelter". Report for 1994. Chornobyl, 1994, 134 p. (in Russian)

[17] Survey of properties of fuel containing materials in "Shelter". Report of the department for radioactive and fuel containing materials at the object "Shelter". National Ukrainian Academy of Sciences-Chornobyl, 1994, 100 p. (in Russian).

[18] Results of the investigation of water accumulations in the premises of the object "Shelter". Suggestion of countersteps. Report. Chornobyl, 1993, 16 p. (in Russian).

[19] Gathering, handling and generalization of data on the version as to lava-shaped fuel containing materials formation. Final report in accordance with the contract 180/94 since 09.94. Khlopin Radium Institute. Saint Peterburg-Chornobyl, 1995, 160 p. (in Russian).

[20] Badovskii V.P., Dubar L.V., Shevchenko S.V. On the problem of nuclear safety of fuel containing materials at the modification of the object "Shelter". Int.Sci.Tech.Center of Nat.Ukr.Acad.Sci "Shelter", 1995, 17 p. (in Ukrainian).

[21] Modelling of the chemical interaction of fuel containing materials with water and 
atmosphere in the object "Shelter". Annotated report. Chornobyl, 1994, 6 p. (in Russian).

[22] Statement on radionuclide content determination for water probes taken from premises of the object "Shelter" 23.02.1995. Chornobyl, 1995, 2 p. (in Russian).

[23] Technical substantiation of nuclear safety of the object "Shelter". Belyajev S.T., Borovoi A.A., Volkov K.G. et al. Moscow, Chornobyl complex expedition at Kurchatov Inst. Atom. Energy, 1990, 160 p. (in Russian).

[24] An estimate of $(\alpha, n)$ reaction contribution into neutron intensivity, generated inside fuel containing materials in premises 305/2 of the object "Shelter". Technical certificate. Minsk, 1995, (Sci. Ind. Center "Kamerton"), p. 1-6 (in Russian).

[25] Evaluation of neutron fields' properties for models of fuel containing materials in the Central hall of the object "Shelter" and their variation in the case of covering with water. Minsk, 1995, (Sci. Ind. Center "Kamerton"), 5 p. (in Russian).

[26] Geguzin Ya.E., Krivoglaz M.A. Movement of macroscopic inclusions in solids. Moscow, Metallurgia, 1971, 344 p. (in Russian).

[27] Davydov Ju.P. State of radionuclides in solutions. Minsk, Nauka, Technika, 1978, 223 p. (in Russian).

[28] Siborg G.T., Cuts J.J. The chemistry of actinide elements. Moscow, Atomizdat, 1960, 541 p. (in Russian).

[29] Felts A. Amorphous and glassy inorganic solids. Moscow, Mir, 1986, 556 p. (in Russian).

[30] Belousov Ju.A., Pushkarev M.V. On the calculation of viscosity for glassy silicate materials in wide assortments of content. // Phys. Chem. of Glass, 1994, vol. 20, No 3, p. 349-360. (in Russian).

[31] Stefanovskii S.V., Ivanov I.A., Gulin A.N. Structure of alumophosphate glasses simulating glassed active wastes on evidence from infrared and paramagnetic spectroscopy. // Phys. Chem. of Glass, 1994, vol. 20, No 2, p. 154-162 (in Russian).

[32] Kuryliak I.J., Tokarchuk M.V. Statistical theory of electrolyte solutions transport through membrane structures. // Ukr. Fiz. Zhurn., 1991, vol. 36, No 8, p. 1179-1185 (in Ukrainian).

[33] Tokarchuk M.V., Omelyan I.P., Zhelem R.I. On the statistical theory of electrolyte solutions transport through membrane structures. Diffusion coefficients. // Cond. Mat. Phys., 1993, No 2, p. 94-102 (in Ukrainian).

[34] Yukhnovskii I.R., Holovko M.F. Statistical theory of classical equilibrium systems. Kiev, Naukova Dumka, 1980, 372 p. (in Russian).

[35] Kuryliak I.J. Equilibrium statistical theory and membrane processes of electrolyte separation. Kyjiv, 1983, 26 p. Preprint of Inst. Theor. Phys. Ukr. Acad. Sci., ITP$82-130 \mathrm{P}$ (in Russian).

[36] Yukhnovskii I.R., Holovko M.F., Sovyak N.E. Screened potentials of spatially inhomogeneous ion-molecular systems. Kyjiv, 1982, 18 p. Preprint of Inst. Theor. Phys. Ukr. Acad. Sci., ITP-82-159P (in Russian).

[37] Bogolyubov N.N. Problems of dynamic theory in statistical physics. In book: Bogolyubov N.N. Collected papers in three volumes. Vol. 2, Kiev, Naukova Dumka, 1970, 99 p. (in Russian).

[38] Blum L. Mean spherical model for asymmetric electrolytes I. Method of solution. // Mol. Phys., 1975, vol. 30, No 5, p. 1529-1535.

[39] Yukhnovskii I.R., Tokarchuk M.V., Omelyan I.P., Zhelem R.I. Statistical theory of diffusion of radionuclides in the ground and underground water I. Statistical model. Lviv, 1994. Preprint ICMP-94-7E, 20 p.

[40] Yukhnovskii I.R., Ivankiv O.L., IgnatyukV.V., Dmytriv G.S., Tokarchuk M.V. Problems of description of nuclear, physical and chemical processes in nuclear magma inside the object "Shelter" I. Radiolysis in "nuclear magma - water" system. Lviv, 1996. Preprint ICMP-96-05U, 16 p. (in Ukrainian).

[41] Yukhnovskii I.R., Omelyan I.P., Sovyak E.M., Zhelem R.I., Tokarchuk M.V. Problems of description of nuclear, physical and chemical processes in nuclear magma inside the object "Shelter" II. Description of diffusion processes in "nuclear magma - water" system. Lviv, 1996. Preprint ICMP-96-06U, 19 p. (in Ukrainian).

[42] Yukhnovskii I.R., Kobryn A.E., Muzychuk A.O., Tokarchuk M.V. Problems of description of nuclear, physical and chemical processes in nuclear magma inside the object "Shelter" III. Statistical description of transfer processes in nuclear magma. Lviv, 1996. Preprint ICMP-96-07U, 8 p. (in Ukrainian).

[43] Report of the Department for Theoretical Problems of Physico-Chemical Processes in Matter containing Radioactive Elements of the Branch of Radioactive Technologies of Materials of Interbranch Scientific and Technical Center "Shelter" of the Ukrainian 
National Academy of Sciences in 1995. Chornobyl, 1995, 33 p. (in Ukrainian).

[44] Belustin A.A. Concentration distribution for ions in surface layers of alkali silicate glasses processed with water solutions. // Phys. Chem. of Glass, 1981, vol. 7, No 1, p. 257-277 (in Russian).

ПРО ОПИС СТРУКТУРНОГО РОЗПОДІЛУ ТА ДИФУЗІЇ

РАДІОАКТИВНИХ ЕЛЕМЕНТІВ У СИСТЕМІ “СКЛОПОДІБНА ЯДЕРНА МАГМА - ВОДА"

І.Р.Юхновський, М.В.Токарчук, І.П.Омелян, Є.М.Сов'як, Р.І.Желем

Проаналізовано стан радіаційної та ядерної безпеки об'єкту “Укриття". Динаміку радіоактивних частинок у склоподібній ядерній магмі пропонується дослідити 3 допомогою рівнянь дифузії, котрі враховують процеси радіоактивних перетворень. Сформульовано найпростішу модель системи "склоподібна ядерна магма - вода" і проведено розрахунок профілів густини радіоактивних частинок. 